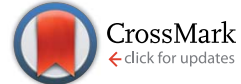

Received 1st November 2015 Accepted 21st January 2016

DOI: $10.1039 / c 5 r a 22940 e$

www.rsc.org/advances
Cite this: RSC Adv., 2016, 6, 14474

\section{Self-assembly of porous copper oxide hierarchical nanostructures for selective determinations of glucose and ascorbic acid $\dagger$}

\author{
Bahaa G. Mahmoud, ${ }^{a}$ Mohamed Khairy, ${ }^{* a}$ Farouk A. Rashwan, ${ }^{a}$ Christopher W. Foster ${ }^{b}$ \\ and Craig E. Banks*b
}

\begin{abstract}
The simple design of $\mathrm{CuO}$ micro-/nanostructures has recently attracted tremendous interest particularly for the enzyme-less sensing of biological molecules due to their intrinsic electronic and catalytic properties. Consequently attention has been directed to the development of new $\mathrm{CuO}$ nanomaterials that have multi-interdisciplinary applications. Herein, we report for the first time the fabrication of hierarchical porous $\mathrm{CuO}$ micro-/nanostructures with flower- and hollow sphere-like morphology via a facile hydrothermal method. Our experimental findings clarify that the source of the copper-ions effectively control the assembly of $\mathrm{CuO}$ nano-building blocks via the one-step hydrolysis of $\left[\mathrm{Cu}\left(\mathrm{NH}_{3}\right)_{4}\left(\mathrm{H}_{2} \mathrm{O}\right)_{2}\right] \mathrm{SO}_{4}$ and $\left[\mathrm{Cu}\left(\mathrm{NH}_{3}\right)_{4}\left(\mathrm{H}_{2} \mathrm{O}\right)_{2}\right] \mathrm{Cl}_{2}$ precursors, which produce hollow sphere and flower-like morphologies for sensitive and selective determination of ascorbic acid and glucose, respectively. Moreover, such unique properties of macro-/mesoporous $\mathrm{CuO}$ with defined dimensions and topologies offer minimized diffusive resistance for the dispersion of active sites. The best performance of the glucose and ascorbic sensor can be obtained at $+0.55 \mathrm{~V}$ in $0.1 \mathrm{M}$ sodium hydroxide solution. The as-prepared $\mathrm{CuO}$ modified (drop-casted) screen-printed electrodes (SPE) exhibit a fast electroactive response with high sensitivity within a wide concentration range of glucose and ascorbic acid in real samples. Significantly, the aniondependent approach might be used to control effectively the expansion and features of other metal oxide micro-/nanostructures.
\end{abstract}

\section{Introduction}

The synthesis of transition metal oxide nanostructures with controlled shapes and sizes has been developed over recent decades due to their shape/size-dependent physical, chemical, electrical, optical, and catalytic properties. ${ }^{\mathbf{1 , 2}}$ They exhibit versatile functions of their energy gap, numerous valence states, and tunable performances for electron transport. This is because their complex morphology and high dimensionality lead to an advanced geometric structure and atom arrangement on the specific facets which provide novel characteristics. To date, hierarchical metal oxide micro-/nanostructures have attracted considerable attention, because of their technological and fundamental scientific importance and potential applications; including chemical and electrochemical sensing,

${ }^{a}$ Chemistry Department, Faculty of Science, Sohag University, Sohag, Egypt. E-mail: mohamed.khairy@science.sohag.edu.eg

${ }^{b}$ Faculty of Science and Engineering, School Science and the Environment, Division of Chemistry and the Environment, Manchester Metropolitan University, Chester Street, Manchester M1 5GD, UK. E-mail: c.banks@mmu.ac.uk; Fax: +44 (0)1612476831; Tel: +44 (0)1612471196

$\dagger$ Electronic supplementary information (ESI) available: Additional cyclic voltammetry and amperometric measurements of glucose and ascorbic acids were added. See DOI: 10.1039/c5ra22940e catalysis, nanoelectronics and nanophotonics. ${ }^{3-6}$ These hierarchical porous micro-/nanostructures offer minimized diffusion resistance, high surface area and good conductivity. ${ }^{7}$ Therefore, numerous hierarchical metal oxides micro-/nanostructures have been recently reported..$^{8-12}$ Direct hydrothermal via hydrolysis of metal salts and sacrificial templates strategies have been widely used to control fabrication of hierarchical structures, yet technical challenges in terms of cost-intensive and time-consuming synthetic conditions remain. In this respect, development of suitable synthetic strategies is highly desirable.

Copper oxide $(\mathrm{CuO})$ is a nontoxic, low cost p-type semiconductor with a narrow-band gap of $1.2 \mathrm{eV}$, which has gained much attention because of its intrinsic electronic and catalytic properties. Such properties have allowed for its wide application within many disciplines ranging from conversion of solar energy, ${ }^{13}$ lithium ion batteries, ${ }^{\mathbf{1 4}}$ supercapacitors, ${ }^{15}$ heterogeneous catalysis, ${ }^{16}$ and electrochemical sensor. ${ }^{12,17}$ Among these potential applications, the exploration of enzyme-less electrochemical sensor especially for glucose has been intensively investigated. ${ }^{17,18}$ Successful synthesis strategies have been employed to control the morphology of $\mathrm{CuO}$ nanostructures as nanowires, ${ }^{19}$ nanobelts, ${ }^{20}$ nanoplatelets, ${ }^{21}$ nanospheres, ${ }^{22}$ nanorods, ${ }^{23}$ and nanofibres. ${ }^{24}$ Recently, a new class of 
hierarchical $\mathrm{CuO}$ micro-/nanostructures has been studied for the extension of its sensing applications. ${ }^{12,19,25}$ Sun et al., ${ }^{18 a}$ reported the fabrication of hierarchical $\mathrm{CuO}$ nanoribbons using a green water/ethanol solution-phase hydrolysis of $\mathrm{Cu}_{x}(\mathrm{OH})_{2 x-2}\left(\mathrm{SO}_{4}\right)$ precursors. Such nanoporous $\mathrm{CuO}$ ribbons show a high sensitivity, low detection limit, and a good selectivity towards glucose. However, the relationships between the copper ion source, additives and morphology are not clear yet.

Diabetes is a chronic disease that occurs usually when the pancreas does not produce sufficient insulin. Unfortunately, about 387 million over the world living with diabetes, more than $77 \%$ of diabetes deaths occur in developing countries. ${ }^{26}$ Certainly, several efforts have focused upon developing of a cheap, stable and reliable sensor for self-monitoring of blood glucose levels as one modality that can help people to improve their glycemic control. ${ }^{27}$

Furthermore, ascorbic acid known as vitamin C, is a powerful antioxidant, which naturally occurs within citrus fruits and vegetable products. Significantly, the determination of ascorbic acid within biological fluids is very important to assess the amount of oxidative stress in the human metabolism, a process that has been linked to cancer, diabetes mellitus and several liver diseases. ${ }^{28}$ Over recent decades, the allure of electrochemical techniques has provided a broad array within environmental monitoring and clinical diagnostics. The development of an enzyme-less electrode has attracted considerable attention due to its simple, low fabrication cost, long term stability and good reproducibility which are the limitations of those enzymatic biosensors. However, the selectivity of the electrode sensor for target analytes is still great challenge. ${ }^{29}$

In this manuscript, we report a novel, effective design structure based on the 'bottom-up' self-assembly of elementary nano-building blocks of $\mathrm{CuO}$ nanostructures. The effect of copper ions source upon the $\mathrm{CuO}$ nanostructures assembly is explored for the first time. These unique micro/nanostructures are then utilised to produce disposable screen-printed electrodes. Additive-free, large-scale production and simple fabrication strategy of hierarchical $\mathrm{CuO}$ micro-/nanostructures were developed via one-step hydrolysis of $\left[\mathrm{Cu}\left(\mathrm{NH}_{3}\right)_{4}\left(\mathrm{H}_{2} \mathrm{O}\right)_{2}\right] \mathrm{SO}_{4}$ and $\left[\mathrm{Cu}\left(\mathrm{NH}_{3}\right)_{4}\left(\mathrm{H}_{2} \mathrm{O}\right)_{2}\right] \mathrm{Cl}_{2}$ precursors without any post-thermal treatment (Scheme 1). Such results show that this anion-

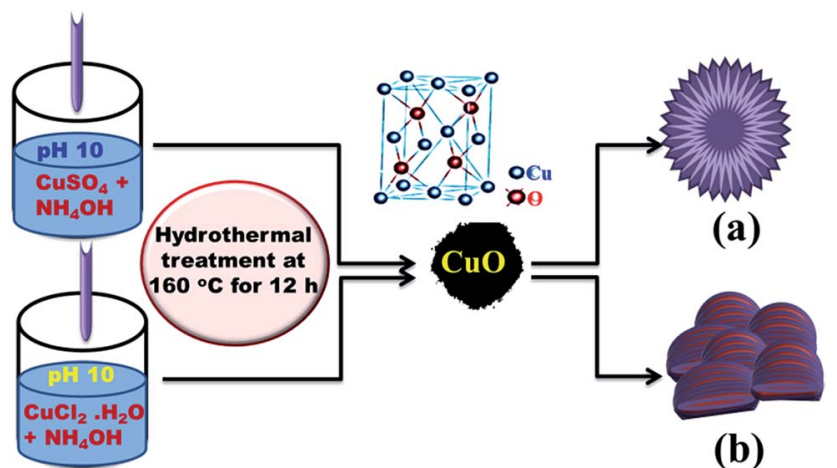

Scheme 1 A schematic representation of the hydrothermal pathway of the copper-ion source hydrolysis approach. dependent approach would effectively optimize the selfassembly of $\mathrm{CuO}$ nanoneedle and nanoplate building blocks to construct hallow sphere- and flower-like morphology, respectively. Interestingly, the nano-building block assembly of $\mathrm{CuO}$ micro-/nanostructures is of great significance in green design of simple, low-cost, and sensitive enzyme-less SPE for selective determination of glucose and ascorbic acid in real samples.

\section{Experimental section}

\subsection{Reagents}

All materials were used without any further purification. Cupric chloride dihydrate $\left(\mathrm{CuCl}_{2}, 99.9 \%\right)$, anhydrous copper sulphate $\left(\mathrm{CuSO}_{4}, 99.9 \%\right)$, ammonia solution $\left(\mathrm{NH}_{4} \mathrm{OH}\right) 28 \%$, L-ascorbic acid, D-glucose, lactose, maltose and sodium hydroxide were all obtained from Sigma-Aldrich Company Ltd.

\subsection{Synthesis of $\mathrm{CuO}$ micro-/nanostructures}

The fabrication of $\mathrm{CuO}$ flower- and sphere-like morphologies were carried out utilising a typical hydrothermal procedure, with $1.70 \mathrm{~g}$ of copper chloride dihydrate and $1.59 \mathrm{~g}$ of anhydrous copper sulphate precursors respectively dissolved (under constant stirring) in $50 \mathrm{~mL}$ deionized water. The solutions were introduced into a $100 \mathrm{~mL}$ Teflon-lined, stainless steel autoclaves. Then, the solutions were adjusted to $\mathrm{pH} 10 \mathrm{using}$ ammonium solution $\left(\mathrm{NH}_{4} \mathrm{OH}, 28 \%\right)$. The autoclaves were sealed and maintained at $160{ }^{\circ} \mathrm{C}$ for 12 hours. Subsequently, these solutions were kept at room temperature. The black precipitates were collected, washed several times with water and ethanol to remove the remaining agents, and then dried at $45{ }^{\circ} \mathrm{C}$ for 6 hours.

\subsection{Fabrication of screen-printed electrodes (SPEs)}

The screen-printed graphite electrodes were fabricated at Manchester Metropolitan University utilising appropriate stencil designs with a microDEK 1760RS screen-printing machine (DEK, Weymouth, UK). For each of the screen-printed sensors a carbon-graphite ink formulation (Product Code: product code: C2000802P2; Gwent Electronic Materials Ltd, UK) was first screen-printed onto a polyester flexible film (Autostat, $250 \mu \mathrm{m}$ thickness). ${ }^{30}$ This layer was cured in a fan oven at 60 degrees Celsius for $30 \mathrm{~min}$. Next, a silver/silver chloride (40:60) reference electrode was applied by screen-printing $\mathrm{Ag} / \mathrm{AgCl}$ paste (Product Code: C2040308P2; Gwent Electronic Materials Ltd, UK) onto the plastic substrate. This layer was once more cured in a fan oven at 60 degrees Celsius for $30 \mathrm{~min}$. Last a dielectric paste ink (Product Code: D2070423P5; Gwent Electronic Materials Ltd, UK) was printed to cover the connections and define the $3 \mathrm{~mm}$ diameter graphite working electrode. After curing at 60 degrees Celsius for $30 \mathrm{~min}$ the screen-printed electrode is ready to use. Similar screen-printed platforms have been electrochemically characterized in a previous contribution. ${ }^{31,32}$

\subsection{Fabrication of $\mathrm{CuO}$ electrodes}

The CuO micro/nanostructure "paste" was prepared as previously reported by Grätzel et al. ${ }^{33}$ Briefly, $30.0 \mathrm{mg}$ of CuO sample 
was mixed and sonicated for 10 min with a mixture of $5 \mu \mathrm{L}$ acetic acid, $5 \mu \mathrm{L}$ deionized water and $17.5 \mu \mathrm{L}$ ethanol in glass beaker (1). A mixture (2) containing $100 \mu \mathrm{g}$ of ethyl cellulose dissolved in $150 \mu \mathrm{L}$ ethanol and $135 \mu \mathrm{L}$ water were introduced into glass beaker (1). Then, $5 \mu \mathrm{L}$ of the paste was drop-casted onto the screen-printed electrode (SPE) surface and left it to dry in oven at $50{ }^{\circ} \mathrm{C}$ for 24 hours.

\subsection{Amperometric measurements}

The CuO-SPEs were activated in $0.1 \mathrm{M} \mathrm{NaOH}$ solution by successively sweeping from -1.0 to $0.8 \mathrm{~V}$ until the electrochemical signal became stable. A holding potential of $+0.55 \mathrm{~V}$ was applied to the CuO-SPEs and the background current was allowed to decay to a steady state. The amperometric response was recorded as a function of glucose or ascorbic acid concentrations in the cell containing $20 \mathrm{~mL}$ of $0.1 \mathrm{M} \mathrm{NaOH}$ solution.

\subsection{Real sample analysis}

Human blood and urine samples were collected from volunteers in hospital of Sohag University. The blood samples were centrifuged (3500 rpm/5 min). The supernatant of which was blood serum was obtained. $200 \mu \mathrm{L}$ blood serum sample was injected into $19.8 \mathrm{~mL}$ of a stirring solution of $0.1 \mathrm{M} \mathrm{NaOH}$. The amperometric current response was recorded using $\mathrm{CuO} \mathrm{MF}-$ SPE and a standard addition method was used to determine the glucose concentration. As well as, $200 \mu \mathrm{L}$ urine sample was injected into $19.8 \mathrm{~mL}$ of a stirring solution of $0.1 \mathrm{M} \mathrm{NaOH}$. The amperometric current response was recorded using $\mathrm{CuO} \mathrm{HS}-$ SPE and a standard addition method was used to determine the ascorbic acid concentration.

\subsection{Characterization of $\mathrm{CuO}$ micro-/nanostructures}

The morphology of the as-synthesized CuO samples were investigated using field emission scanning electron microscopy (FE-SEM, JEOL model 6500). Before insertion into the chamber, the $\mathrm{CuO}$ powders were ground and fixed onto a specimen stub using double-sided carbon tape. Then, a $10 \mathrm{~nm}$ Pt film was coated via anion sputtering (Hitachi E-1030) at room temperature to obtain high-resolution micrographs. For better recording of FE-SEM images, the SEM was operated at $15 \mathrm{keV}$.

High-resolution transmission electron microscopy (HRTEM), electron diffraction (ED), and energy dispersive X-ray spectroscopy for elemental analysis (EDS) were performed using a JEOL JEM model 2100F microscope. HR-TEM was conducted at an acceleration voltage of $200 \mathrm{kV}$ to obtain a lattice resolution of $0.1 \mathrm{~nm}$. The HRTEM images were recorded using a CCD camera. In the HRTEM, ED and EDS characterization, the $\mathrm{CuO}$ samples were dispersed in ethanol solution using an ultrasonic bath, and then dropped on a copper grid. Prior to inserting the samples into the HRTEM column, the grid was vacuum dried for $20 \mathrm{~min}$.

Wide-angle powder X-ray diffraction (XRD) patterns were measured X-ray diffractometer (Model FW 1700 series, Philips, Netherlands) using with monochromated $\mathrm{CuK} \alpha$ radiation $(\lambda=$ $1.54 \AA$ ), employing a scanning rate of $0.06^{\circ} \mathrm{min}^{-1}$ and $2 \theta$ ranges from $4^{\circ}$ to $80^{\circ}$. The diffraction data were analysed using the
DIFRAC plus Evaluation Package (EVA) software with the PDF-2 Release 2009. The Fourier transform infrared (FTIR) spectra of the $\mathrm{CuO}$ samples were recorded using Bruker Alpha FTIR instrument.

The textural surface properties and pore size distribution was determined by $\mathrm{N}_{2}$ adsorption/desorption isotherms at $77 \mathrm{~K}$ with a BELSORP36 analyzer (JP. BEL Co., Ltd.). The specific surface area $\left(S_{\mathrm{BET}}\right)$ was calculated using the Brunauer-EmmettTeller (BET) method with multipoint adsorption data from the linear segment of the $\mathrm{N}_{2}$ adsorption isotherm. The pore size distribution was determined from the analysis of desorption branch of isotherm using the nonlocal density functional theory (NLDFT).

The electrochemical experiments were performed using Autolab $302 \mathrm{~N}$ potentiostat/galvanostat workstation. All measurements were conducted using a screen-printed electrode configuration. During the development of the protocol, the 3 $\mathrm{mm} \mathrm{CuO}$ modified graphite working electrode of the screenprinted electrode was used with a platinum counter electrode and $\mathrm{Ag} / \mathrm{AgCl}$ as reference electrode. Connectors for the efficient connection of the screen-printed electrochemical sensors were purchased from Kanichi Research Services Ltd (UK). ${ }^{34}$

\section{Result and discussion}

\subsection{Formation mechanism of hierarchical CuO micro-/ nanostructures}

The copper oxide micro/nanostructures were fabricated as described in the Experimental section. Control over the particle morphology of $\mathrm{CuO}$ was clearly evident by using one-pot, simple hydrothermal synthesis (Scheme 1). Interestingly, it was noted that, the copper-ion precursors were effectively controlling the self-assembly of $\mathrm{CuO}$ nanoparticles within the hierarchical structures. The induced-water hydrolysis of $\left[\mathrm{Cu}\left(\mathrm{NH}_{3}\right)_{4}\left(\mathrm{H}_{2} \mathrm{O}\right)_{2}\right]$ $\mathrm{SO}_{4}$ and $\left[\mathrm{Cu}\left(\mathrm{NH}_{3}\right)_{4}\left(\mathrm{H}_{2} \mathrm{O}\right)_{2}\right] \mathrm{Cl}_{2}$ was exploited for the formation of hierarchical $\mathrm{CuO}$ with sphere and flower morphologies, respectively. The suggested mechanism for the formation of $\mathrm{CuO}$ micro-/nanostructures involves a three-stage process and is as follows. Cupper(II) ion forms distorted octahedral complexes $\left[\mathrm{Cu}\left(\mathrm{H}_{2} \mathrm{O}\right)_{6}\right] \mathrm{Cl}_{2}$ and $\left[\mathrm{Cu}\left(\mathrm{H}_{2} \mathrm{O}\right)_{6}\right] \mathrm{SO}_{4}$ in water. Upon small additions of $\mathrm{NH}_{4} \mathrm{OH}$ solution, $\mathrm{Cu}(\mathrm{OH})_{2}$ primary crystals are formed. Continued addition of $\mathrm{NH}_{4} \mathrm{OH}$ solution leading to the formation of soluble deep blue complexes of $\left[\mathrm{Cu}\left(\mathrm{NH}_{3}\right)_{4}\left(\mathrm{H}_{2} \mathrm{O}\right)_{2}\right] \mathrm{Cl}_{2}$ and $\left[\mathrm{Cu}\left(\mathrm{NH}_{3}\right)_{4}\left(\mathrm{H}_{2} \mathrm{O}\right)_{2}\right] \mathrm{SO}_{4}$ which prevent spontaneous precipitation, and the eventual leading to the formation of a supersaturated solutions. ${ }^{18}$ Under hydrothermal conditions and heating at 160 ${ }^{\circ} \mathrm{C}$, the solution becomes saturated; the ionic species exceed the solubility product by the release of $\mathrm{H}_{2} \mathrm{O}$ and $\mathrm{NH}_{3}$ molecules. According to the previous reports, ${ }^{18}$ The $\mathrm{OH}^{-}$ions replace $\mathrm{NH}_{3}$ in their complexes giving rise to layered structure of $\mathrm{Cu}_{2}$ $(\mathrm{OH})_{3} \mathrm{Cl}$, and $\mathrm{Cu}_{3}(\mathrm{OH})_{4} \mathrm{SO}_{4}$ units in strong alkaline solutions (eqn (1-1), (1-2), (2-1) and (2-2)). These units of $\mathrm{Cu}_{2}(\mathrm{OH})_{3} \mathrm{Cl}$, and $\mathrm{Cu}_{3}(\mathrm{OH})_{4} \mathrm{SO}_{4}$ would be rapidly converted into charged and highly anisotropic $\mathrm{Cu}(\mathrm{OH})_{2}$ nuclei by water molecules. Wen et al.; ${ }^{18 b}$ suggested that, $\mathrm{Cu}(\mathrm{OH})_{2}$ nanoribbons preferentially grow along the [100] direction due to assembly of $>\mathrm{Cu}(\mathrm{OH})_{2} \mathrm{Cu}_{\checkmark}$ chains. As well as, the layer structures parallel to [010] direction 
are connected via hydrogen bonding between the tetracoordinated $\mathrm{OH}^{-}$groups and two neighbouring bicoordinated hydroxyls. Therefore, a ribbon-like structure was developed. Moreover, the counter ions $\mathrm{Cl}^{-}$and $\mathrm{SO}_{4}{ }^{2-}$ might be adsorbed on the (010) surface, which slow the growth along the [010] direction and control the stacking of nanoplates and nanoneedles to form flower and hollow sphere morphologies. Further, the sulphate oxygen atom helps to cross-link two adjacent layers and hence, strongly contributes to the formation of the three dimensional architectures. The $\mathrm{Cu}(\mathrm{OH})_{2}$ is a metastable phase which is easily transformed to the more stable $\mathrm{CuO}$ by thermal dehydration in aqueous media, because the solubility of $\mathrm{Cu}(\mathrm{OH})_{2}$ is $1.3 \times 10^{-5} \mathrm{~mol} \mathrm{~L}^{-1}$ which is higher than that of $\mathrm{CuO}\left(2 \times 10^{-7} \mathrm{~mol} \mathrm{~L}^{-1}\right)$. By releasing of water molecules, the $\mathrm{Cu}(\mathrm{OH})_{2}$ converted to monoclinic $\mathrm{CuO}$ due to oxolation process at a relatively higher temperature without a trace of the subsequent annealing treatment in air (eqn (3)). Hence, the copper ions source can modify the subsequent precipitation process, which might affect the competition between thermodynamics and kinetics during the transformation of precursors, nucleation, growth and assembly of $\mathrm{CuO}$ nanostructures (see the following equations).

$$
\begin{gathered}
3 \mathrm{Cu}^{2+}+4 \mathrm{OH}^{-}+\mathrm{SO}_{4}{ }^{2-} \rightleftharpoons \mathrm{Cu}_{3}(\mathrm{OH})_{4} \mathrm{SO}_{4} \\
2 \mathrm{Cu}^{2+}+3 \mathrm{OH}^{-}+\mathrm{Cl}^{-} \rightleftharpoons \mathrm{Cu}_{2}(\mathrm{OH})_{3} \mathrm{Cl} \\
\mathrm{Cu}_{3}(\mathrm{OH})_{4} \mathrm{SO}_{4}+2 \mathrm{H}_{2} \mathrm{O} \rightleftharpoons 3 \mathrm{Cu}(\mathrm{OH})_{2}+2 \mathrm{H}_{2} \mathrm{SO}_{4} \\
\mathrm{Cu}_{2}(\mathrm{OH})_{3} \mathrm{Cl}+\mathrm{H}_{2} \mathrm{O} \rightleftharpoons 2 \mathrm{Cu}(\mathrm{OH})_{2}+\mathrm{HCl} \\
\mathrm{Cu}(\mathrm{OH})_{2} \rightleftharpoons \mathrm{CuO}+\mathrm{H}_{2} \mathrm{O}
\end{gathered}
$$

Fig. 1(A-D), shows the FE-SEM images of hierarchical CuO microstructures prepared without any additives. The hydrolysis of $\mathrm{CuCl}_{2}$ in the presence of $\mathrm{NH}_{4} \mathrm{OH}$ at $\mathrm{pH} 10$ reveals uniform micro-bunches of $\mathrm{CuO}$ nanoplate clusters assembled in flower-

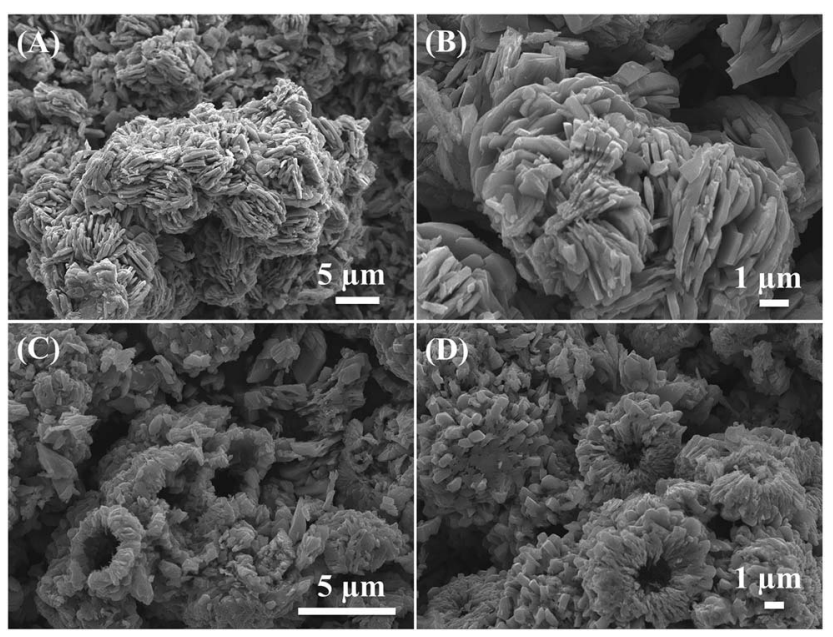

Fig. 1 FE-SEM of CUO microstructures with flower and hallow sphere-like morphology synthesized without any additives using $\mathrm{CuCl}_{2}\left(\mathrm{~A}\right.$ and $\mathrm{B}$ ) and $\mathrm{CuSO}_{4}$ (C and D) precursors, respectively. like morphology (Fig. 1A). The bunches of these microflowers (MF) have an average diameter of $\sim 5 \mu \mathrm{m}$, which the thickness of the aggregated plates $\sim 220 \mathrm{~nm}$. Such high magnification images reveal the formation of densely aggregated nanoplate clusters, with smooth fine surfaces that were aligned according to uniform flower morphology (Fig. 1B). Moreover, it is clearly evident that there is an interlayer spacing as macropores with slit-shape structure between the nanoplate arrays, enhancing the diffusion of ions and molecules to their respective active sites of the $\mathrm{CuO}$ crystals.

While, the hydrolysis of $\mathrm{CuSO}_{4}$ in the same conditions reveals the formation of a hallow sphere (HS) consisting of closely packed nanoneedle arrays (Fig. 1C and D). The average size of aggregated needles is $\sim 230 \mathrm{~nm}$, the diameter of sphere is $\sim 5.60 \mu \mathrm{m}$, and open pores are $\sim 1.66 \mu \mathrm{m}$. Interestingly, the needles are obviously rough and is an assembly of a large number of nanoneedles and voids, leading to the formation of hierarchical hallow sphere-like morphology. Overall, the SEM images demonstrate the versatility of metal-ion source approach over effectively control of the nanoparticle shape and their assembly in hierarchical microstructures.

The high-resolution transmission electron microscopy (HRTEM) images [Fig. 2] clearly indicate that, the CuO MFs and HSs are composed form assembled plates and needles nanoblocks respectively with disordered porous network. These HRTEM images showed the formation of $\mathrm{CuO}$ nanoplates and nanoneedles firstly and then assembled together to form $\mathrm{CuO}$ microstructures with flower- and hollow sphere-like morphology. According to the distinct color contrast of TEM images associated with flower structure (Fig. 2a and b), we could detect that the triangular nanoplate in the core region of flower were more compact than those in the exterior. Fig. $2 \mathrm{~b}$ is a typical HR-TEM image of an individual $\mathrm{CuO}$ nanoplate, and it can be interestingly found that the plate is very thin and obviously rough with size about $270 \mathrm{~nm}$. Moreover, the most prominent feature was that the plate showed uniform arrangements and continuous ordering of lattice fringes over large-scale regions without distortion. The TEM image (Fig. 2c), in general, revealed well-organized lattice fringe arrays over a large area with a distance between two lattice fringes of $0.23 \mathrm{~nm}$ that features the interplanar space of (111) facets of monoclinic crystal lattices. Fig. 2d showed the corresponding selected area electron diffraction pattern (ED) of $\mathrm{CuO}$ nanostructure. The figure shows that the $\mathrm{CuO}$ particles are single crystalline in nature.

The Fig. 2e and $f$ showed the HRTEM images of nanoneedle aggregates to form $\mathrm{CuO}$ hollow sphere. The diameter of the single needle varied from the base to the tip, i.e. sharpened tips with wider bases. The wider base of the needle connected to each other, rooted in the center to form a sphere-like morphology. Fig. $2 \mathrm{~g}$ showed the lattice fringes with an interspacing of $0.23 \mathrm{~nm}$ and $0.2 \mathrm{~nm}$ corresponding to the distance between (111) and (002) facets respectively of the monoclinic $\mathrm{CuO}$ lattice. The representative ED image [Fig. 2h] indicates the high crystallinity of the porous $\mathrm{CuO}$ nanostructures. These results are consistent with the XRD results (see below). 

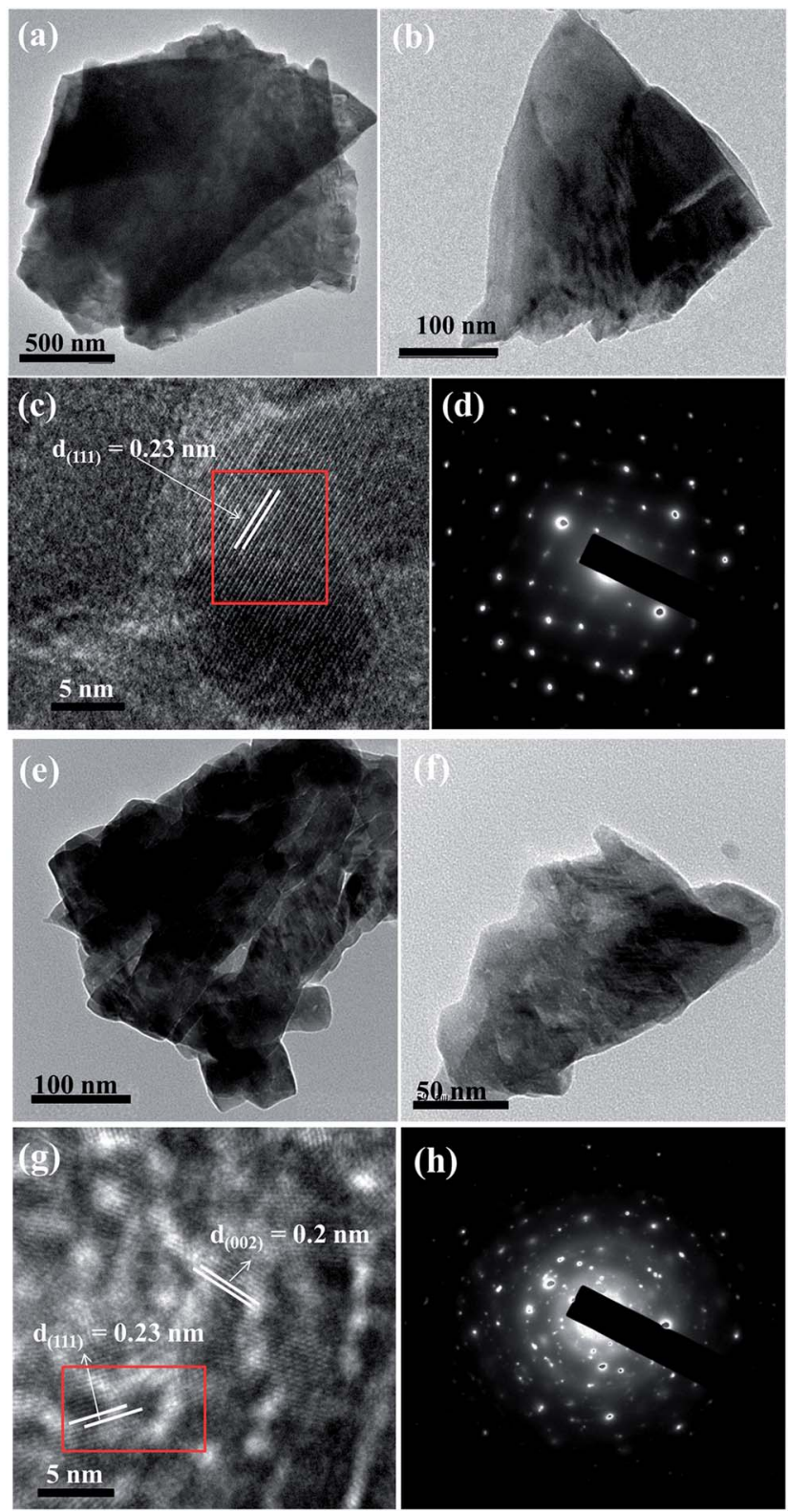

Fig. $2 \mathrm{HR}$-TEM and SAED images of $\mathrm{CuO}$ nanostructures, $(\mathrm{a}-\mathrm{d}) \mathrm{CuO}$ MFs and (e-h) CuO HSs.

\subsection{Structural and textural features}

Fig. 3a shows the wide angle XRD patterns of the hierarchical $\mathrm{CuO}$ microstructures utilising different $\mathrm{Cu}$-ion precursors. It is clear that they exhibit typical diffraction peaks of monoclinic Tenorite CuO phase of (JCPDS, no. 02-1040) and no impurities are detected, indicating that the $\mathrm{CuO}$ microstructures are pure and well crystalline. Although, the anion in copper ion source has largest effects on $\mathrm{CuO}$ morphology, it cause greatly affect on the crystallographic orientation of $\mathrm{CuO}$ nanocrystals.

Fig. $3 \mathrm{~b}$ shows the FTIR spectra of $\mathrm{CuO}$ microstructures. They exhibited strong absorption below $1000 \mathrm{~cm}^{-1}$, which confirmed the formation of the monoclinic $\mathrm{CuO}$ crystal phase. The characteristic peaks at 473.8 and $598.3 \mathrm{~cm}^{-1}$ are due to the vibrational modes of $\mathrm{Cu}-\mathrm{O}$ bond in $\mathrm{CuO}$ HSs, while these shifts
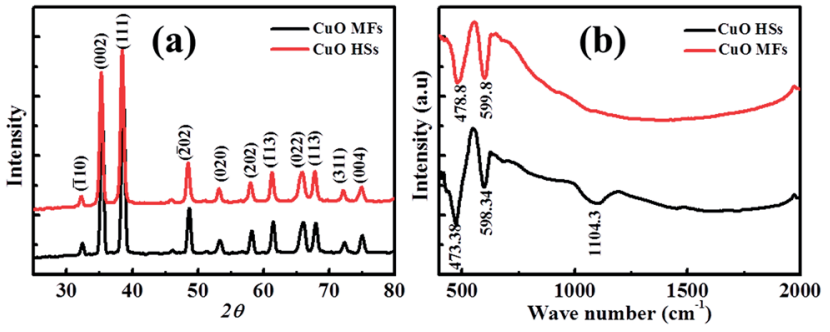

Fig. 3 (a) Wide angle XRD patterns and (b) FTIR spectra of CuO microstructures.

slightly in $\mathrm{CuO}$ MFs. Furthermore, the absorption peak at around $1104 \mathrm{~cm}^{-1}$ may be attributed to $-\mathrm{OH}$ bending vibrations combined with copper atoms. Energy dispersive spectroscopy (EDS) analysis of the CuO microstructures suggested the presence of $\mathrm{Cu}$ and $\mathrm{O}$ signals devoid of any other metal and impurity (Fig. S1 within ESI $\dagger$ ). The $\mathrm{O}$ and $\mathrm{Cu}$ atoms were originally found in the $\mathrm{CuO}$ nanocrystals. The atomic ratios of $[\mathrm{O}] /[\mathrm{Cu}]$ are 0.95 and 1.186 for CuO MFs and HSs respectively. The EDS and FTIR analysis suggested that $\mathrm{CuO}$ HSs have higher content of oxygen atoms on the surface compared to CuO MFs. This significant feature of $\mathrm{CuO}$ microstructures might show comparable electrochemical activity.

The porous network of hierarchical $\mathrm{CuO}$ structures were investigated using nitrogen adsorption/desorption isotherms (Fig. 4). The specific surface areas $S_{\mathrm{BET}}$ were calculated by employing the Brunauer-Emmett-Teller (BET) method and the pore size distributions were obtained by means of the nonlocal density functional theory (NLDFT) equation using the adsorption isotherm branch. The CuO HSs feature type IV isotherms with a $\mathrm{H}_{2}$-type hysteresis loop for typical mesocage materials with large pore cavities. However, CuO MFs show type II isotherms without any hysteresis loops. It is worth noting that the porous CuO samples featured a specific surface area of $S_{\mathrm{BET}}$ $=60.37 \mathrm{~m}^{2} \mathrm{~g}^{-1}$, and $60.24 \mathrm{~m}^{2} \mathrm{~g}^{-1}$, for CuO MFs and HSs respectively. The pore size distribution show bimodal distribution centred at $4.4 \mathrm{~nm}$ and $108 \mathrm{~nm}$ for CuO MFs and $5.4 \mathrm{~nm}$ and $108 \mathrm{~nm}$ for CuO HSs. These results are in accordance with SEM and HR-TEM micrographs (Fig. 1 and 2). In general, the mesopore within the hierarchical $\mathrm{CuO}$ microstructures is probably related to the pores present inside the nanoplates or nanoneedles, which were formed between primary crystallites.
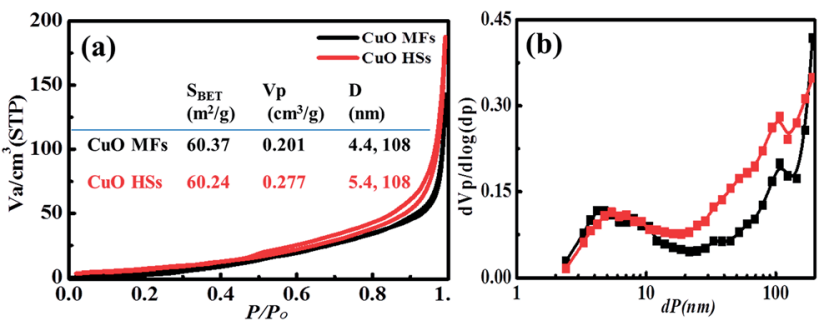

Fig. 4 (a) Nitrogen adsorption-desorption isotherms of $\mathrm{CuO}$ microstructures and (b) their corresponding NLDFT pore size distribution plots. 
However, the macropore is related to assembly of secondary crystals of plates or needles. Such control of hierarchical surface morphologies with well-developed porous network offer great advantageous in electrochemical applications since macropore channels permit fast ions transport, while the mesopores provide more electroactive sites for redox reactions.

\subsection{Electrochemical characterization of hierarchical CuO nanostructures}

The electrochemical activities of the CuO-SPEs were studied by cyclic voltammetry (CV) with $50 \mathrm{mM}$ potassium ferricyanide redox probe $\left[\mathrm{Fe}(\mathrm{CN})_{6}\right]^{3+}$ and $0.1 \mathrm{M} \mathrm{KCl}$ as supporting electrolyte. Fig. 5a and b show a series of cyclic voltammograms recorded as a function of a range scan rates for CuO MF- and CuO HS-SPEs. It is clear that the cyclic voltammograms are not identical with the same experimental setups. They exhibit a quasi-reversible one-electron transfer behaviour with a peak separation $\left(\Delta E_{\mathrm{p}}\right)$ of $c a .213$ and $140 \mathrm{mV}$ (vs. $\mathrm{Ag} / \mathrm{AgCl}$ ) for $\mathrm{CuO}$ $\mathrm{MF}$ and $\mathrm{CuO} \mathrm{HS}$ samples at a scan rate of $10 \mathrm{mV} \mathrm{s}^{-1}$ respectively. However, the $\mathrm{CuO} \mathrm{MF}$ sample exhibits the greatest peak current compared to CuO HS. These variations within the peak current resulting from the dimension of building-up diffusion zone at electrode surface due to the morphological features of $\mathrm{CuO}$ microstructures. ${ }^{35}$ The analysis of the cyclic voltammetric curves of CuO samples were performed, where the peak height $\left(I_{\mathrm{p}}\right)$ was presented as a function of scan rate $(\nu)$ which are found to be linear $\left(\mathrm{CuO} \mathrm{MF}, I_{\mathrm{p}}(\mathrm{A})=20 \times 10^{-6} \mathrm{~A}\left(\mathrm{~V} \mathrm{~s}^{-1}\right)^{-0.5}+\right.$ $10.4 \times 10^{-6} \mathrm{~A}, R^{2}=0.982 ; \mathrm{CuO} \mathrm{HS}, I_{\mathrm{p}}(\mathrm{A})=3.33 \times 10^{-6} \mathrm{~A}$ $\left.\left(\mathrm{V} \mathrm{s}^{-1}\right)^{-0.5}+0.51 \times 10^{-6} \mathrm{~A}, R^{2}=0.987\right)$. It can be clearly seen that the peak current of both $\mathrm{CuO}$ microstructures increases linearly with the increase of the square root of the scan rate, corresponds to diffusion controlled processes governed by the Randles-Ševćik equation. Moreover, the effective surface area of CuO MF is six times higher than that of the CuO HS. The Nicholson method was applied to estimate the observed standard heterogeneous electron transfer rate constant, $k^{\mathrm{o}}$ for quasi-reversible systems. ${ }^{36}$ The $k^{\mathrm{o}}$ values were estimated to be of $2.01 \times 10^{-4}$ and $7.4 \times 10^{-4} \mathrm{~cm} \mathrm{~s}^{-1}$ for CuO MF and CuO HS respectively. The difference in $k^{\mathrm{o}}$ values indicate that hierarchical $\mathrm{CuO}$ microstructures possessed variable electrochemical reactivity, and thus, the investigation of the electrochemical sensing platforms will be promising.
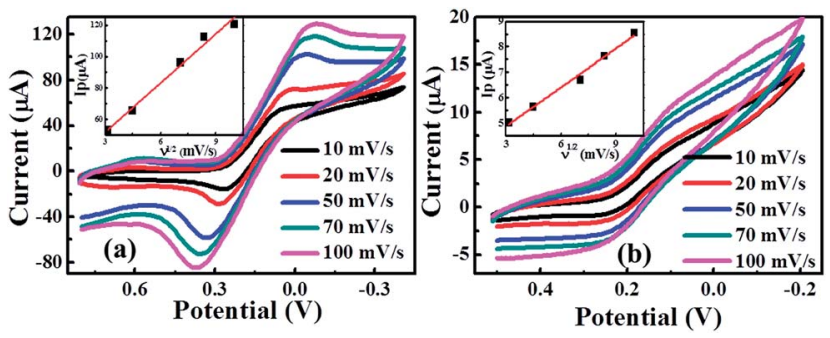

Fig. $5 \mathrm{CV}$ curves of $50 \mathrm{mM}$ potassium ferricyanide/0.1 $\mathrm{M} \mathrm{KCl}$ using $\mathrm{CuO}-\mathrm{SPE}$ electrodes (a) CuO MFs, and (b) $\mathrm{CuO} \mathrm{HSs}$ at different scan rates.

\subsection{Enzyme-less features of hierarchical CuO microstructures}

The electrochemical performance of the hierarchical $\mathrm{CuO}$ micro-/nanostructures modified SPE were investigated by CV in $20 \mathrm{~mL} \mathrm{NaOH}(0.1 \mathrm{M})$ solution as the supporting electrolyte. Fig. 6a depicts $\mathrm{CV}$ curves of $\mathrm{CuO}$ microstructures in absence and presence of $5 \mathrm{mM}$ glucose. There is no obvious current signal observed in the absence of glucose for both CuO-SPE electrodes. After injection of glucose, the oxidation current was increased remarkably at $+0.55 \mathrm{~V}$ (vs. SCE) for CuO MFs however, in the case of the CuO HSs did not show any significant change. Although they were synthesized via the same route, $\mathrm{CuO}$ MFs have a good electrocatalytic activity towards the oxidation of glucose. Interestingly, the anion-dependent approach would effectively control the electrocatalytic activity of $\mathrm{CuO}$ microstructures. In addition, the previous experiments were conducted within phosphate buffer solution ( $\mathrm{pH}$ 7.5) instead of an alkaline medium (Fig. S2 within ESI $\dagger$ ). The $\mathrm{CuO}$ microstructures did not show any current response, which indicates that the $\mathrm{OH}^{-}$ions have a significant role within the electrocatalytic oxidation process. The electrocatalytic oxidation mechanism of glucose onto CuO MFs modified SPE can be described in the following eqn (4)-(6);

$$
\begin{gathered}
\mathrm{CuO}+\mathrm{OH}^{-} \rightarrow \mathrm{CuOOH}+\mathrm{e}^{-} \\
\mathrm{Cu}(\mathrm{III})+\text { glucose }+\mathrm{e}^{-} \rightarrow \text { gluconolactone }+\mathrm{Cu}(\mathrm{II}) \\
\text { Gluconolactone } \rightarrow \text { gluconic acid }
\end{gathered}
$$

Significantly, $\mathrm{CuO} \mathrm{MF}$ was electrochemically oxidized to strong oxidizing agent $\mathrm{Cu}(\mathrm{III})$ species (i.e. $\mathrm{CuOOH}$ ) and then glucose is catalytically oxidized to gluconolactone, which subsequently hydrolysed to gluconic acid. The oxidation of glucose has been also investigated at different scan rates (10$100 \mathrm{mV} \mathrm{s}^{-1}$ ) (Fig. 6b). Noticeably, the oxidation current is linearly correlated with square root of scan rate with slightly positive potential shifts; $I_{\mathrm{p}}(\mathrm{A})=2.94 \times 10^{-6} \mathrm{~A}\left(\mathrm{~V} \mathrm{~s}^{-1}\right)^{-0.5}+31.5 \times$ $10^{-6} \mathrm{~A}, R^{2}=0.98$. This observation reveals that, electrocatalytic oxidation of glucose is governed by a diffusional process.

Fig. 7a shows cyclic voltammograms of successive additions of $1.0 \mathrm{mM}$ glucose into a $20 \mathrm{~mL} \mathrm{NaOH}(0.1 \mathrm{M})$ solution. Upon
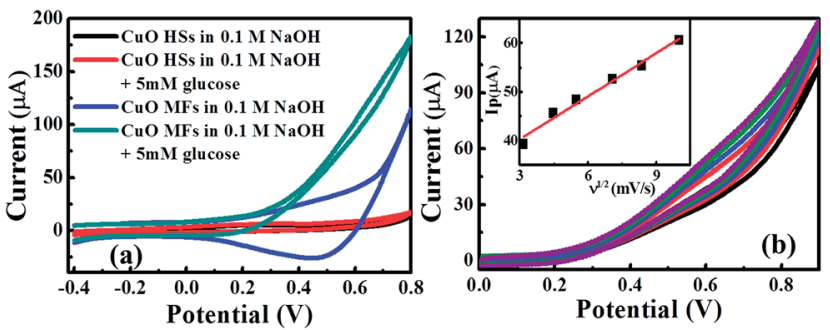

Fig. 6 (a) Cyclic voltammograms of CuO-SPE in $0.1 \mathrm{M} \mathrm{NaOH}$ in absence and presence of $5 \mathrm{mM}$ glucose, and (b) effect of scan rate in a solution of $5 \mathrm{mM}$ glucose and $0.1 \mathrm{M} \mathrm{NaOH}$ onto $\mathrm{CuO}$ MFs [in-set the relation between peak current and square root of scan rate]. 

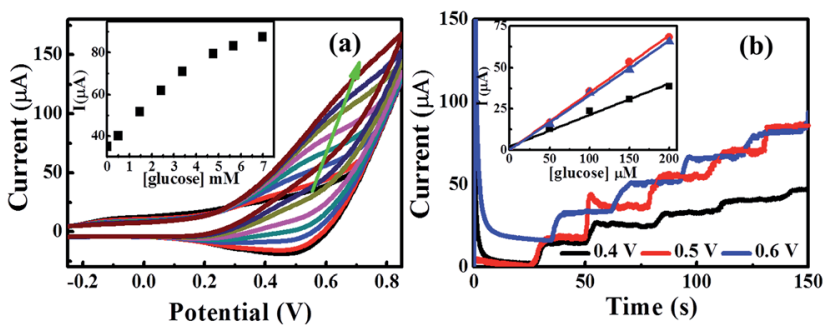

Fig. 7 (a) Cyclic voltammetry of successive additions of $1.0 \mathrm{mM}$ glucose into $20 \mathrm{~mL} \mathrm{NaOH}(0.1 \mathrm{M})$ [in-set the peak current analysis of glucose additions at scan rate: $50 \mathrm{mV} \mathrm{s}^{-1}$ ], (b) amperometric current signals of the CUO MF-SPE under different working potentials upon successive additions of $50 \mu \mathrm{M}$ glucose.

the increase of the glucose concentration, a gradual growth within the current (with positive potential shift) can be observed utilising the CuO MF-SPE. The electrochemical oxidation of glucose was explored over the concentration range of $1 \mathrm{mM}$ to 7 $\mathrm{mM}$, with exceptional linearity; $I_{\mathrm{p}} / \mu \mathrm{A}=10.84 \mu \mathrm{AmM}^{-1}+35.02$ $\mu \mathrm{A}, R^{2}=0.99$.

Furthermore, a chronoamperometric method was utilised to obtain better sensitivity because enhanced analytical signals can be achieved by optimizing the working potential of lower background currents. The effect of applied potential was tested by successive amperometric measurements of $0.5 \mathrm{mM}$ glucose additions into a stirring $0.1 \mathrm{M} \mathrm{NaOH}$ at different potentials ranging from $+0.4 \mathrm{~V}$ to $+0.6 \mathrm{~V}$ (Fig. $7 \mathrm{~b}$ ). The largest sensitivity was observed at $+0.5 \mathrm{~V}$ which also used for the subsequent amperometric measurements.

Fig. 8 is a typical amperometric response of the hierarchical CuO MF-SPE electrode with successive additions of a certain concentration of glucose into continuously stirred $0.1 \mathrm{M} \mathrm{NaOH}$ solution at an applied potential of $+0.55 \mathrm{~V}$ ( $v s$. SCE). Since there was no obvious amperometric response to dissolved oxygen within the $\mathrm{NaOH}$ solution upon a CuO MF-SPE, the glucose can be detected in the presence of oxygen. It was clearly seen that the modified electrode exhibits a fast and sensitive response towards the electrocatalytic oxidation of lower and high concentrations of glucose (Fig. 8a and b). The response time for detection of glucose using CuO MF-SPE is $\sim 2.0$ seconds (in-set Fig. 8b). The amperometric oxidation current increased linearly
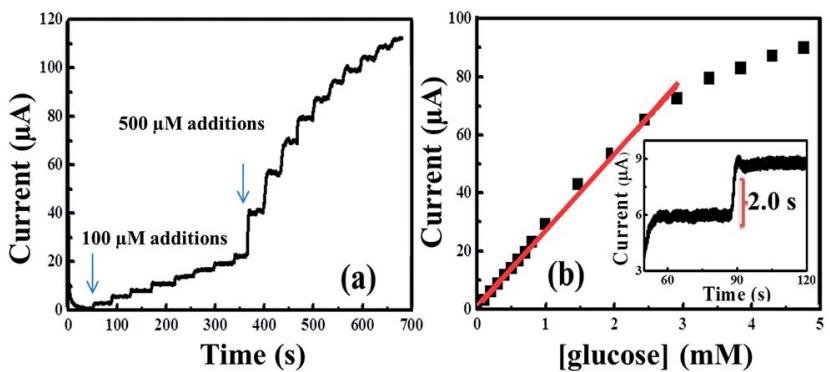

Fig. 8 Typical amperometric current responses of CUO MF-SPE with successive additions of glucose (a) into a stirring $0.1 \mathrm{M} \mathrm{NaOH}$ at +0.55 $\mathrm{V}$. (b) Analysis of the amperometric profiles in terms of the current as a function of glucose concentrations. with increasing concentration of glucose over the concentration ranges $0.05-3 \mathrm{mM} ; I_{\mathrm{p}} / \mu \mathrm{A}=0.027 \mu \mathrm{A} \mu \mathrm{M}^{-1}+0.42 \mu \mathrm{A}, R^{2}=0.99$, $N=3$; with the detection limits of $10 \mu \mathrm{M}(\mathrm{S} / \mathrm{N}=3 \sigma)$ and the sensitivities were estimated to be $383 \mu \mathrm{A} \mathrm{mM}{ }^{-1} \mathrm{~cm}^{-2}$, indicating superior electrocatalytic oxidation behaviour of $\mathrm{CuO} \mathrm{MF}$ toward lower and higher concentration of glucose. Such electrodes show high sensitivities, fast responses, and linear ranges within the realm of blood glucose concentration within the human body (i.e. $2-10 \mathrm{mM}$ ) as shown in Fig. S3, $\dagger$ which is promising in online glucose monitoring compared with other sophisticated sensors reported in the literature. ${ }^{37}$

\subsection{Reproducibility and selectivity of enzyme-less $\mathrm{CuO}$ nanostructures}

The reproducibility of CuO MF- and CuO HS-SPE were investigated by determining $100 \mu \mathrm{M}$ glucose and ascorbic acid respectively in a stirred solution of $(0.1 \mathrm{M}) \mathrm{NaOH}$. Five CuO MFand CuO HS-SPEs were prepared and tested independently, the relative slandered deviation (RSD) of $2.374 \%$ and $1.79 \%$ were obtained. Moreover, successive amperometric measurements of $100 \mu \mathrm{M}$ were repeated on the same electrode which yielded a RSD of $3.7 \%$ and $2.67 \%$ for CuO MF- and CuO HS-SPE respectively.

Next, attention was turn to perform selectivity experiments as one of the significant analytical factors for an amperometric sensor. The selectivity experiments of glucose in a stirred solution of $\mathrm{NaOH}$ were carried out using $\mathrm{CuO}$ MF and CuO HSSPEs in the presence of $1 \mathrm{mM}$ of possible interferes such as lactose, maltose, and ascorbic acid. Interestingly, we found that, the CuO MF- and CuO HS-SPE are highly selective for glucose and ascorbic acid respectively at $+0.55 \mathrm{~V}(v s$. SCE). As shown in Fig. 9a and b, the current responses of CuO MF- and CuO HSSPEs to the oxidation of glucose and ascorbic acid remain almost constant. A good linear relationship can be obtained up to $6 \mathrm{mM}$ of glucose and ascorbic acid even in presence of coexisting electroactive species. Indicating excellent specific
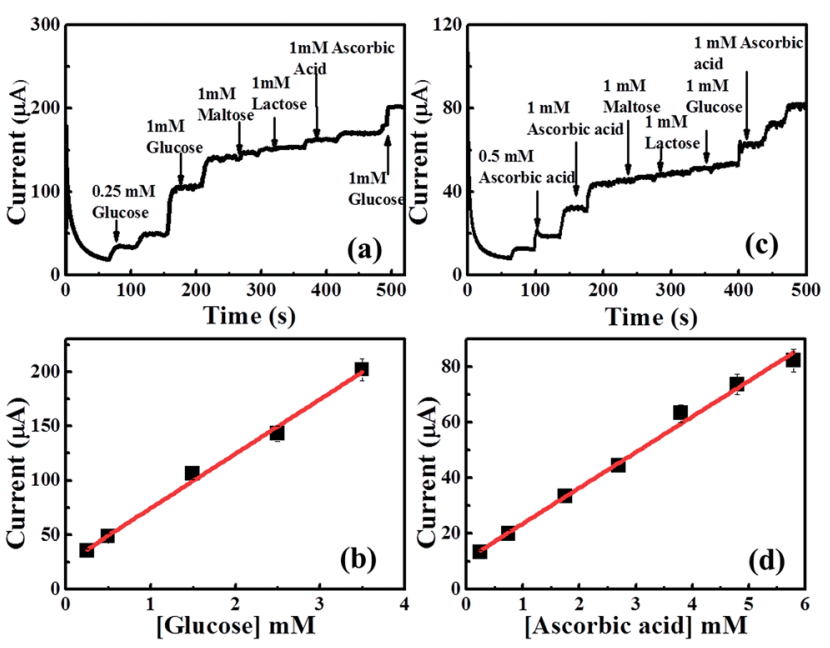

Fig. 9 Amperometric responses of the $\mathrm{CuO} \mathrm{MF}$ and $\mathrm{CuO} \mathrm{HS}$ modified $\mathrm{SPE}$ at $+0.55 \mathrm{~V}$ to $1 \mathrm{mM}$ glucose and $1 \mathrm{mM}$ ascorbic acid respectively and different interfering species in a stirring $0.1 \mathrm{M} \mathrm{NaOH}$. 
selectivity of these CuO MF- and CuO HS-SPEs towards glucose and ascorbic acid respectively (Fig. 9c and d). Such promising selectivity of $\mathrm{CuO}$ microstructures are related to aniondependent approach which effectively optimize the active surface of self-assembled $\mathrm{CuO}$ nano-building blocks in hierarchical structures (Table S4†). The selectivity of CuO micro-/ nanostructures is related to their surface properties. Ascorbic acid is a well-known reducing agent both in vivo and in vitro. ${ }^{38}$ Hence, the oxidation of ascorbic acid is preferentially onto $\mathrm{CuO}$ HSs due to relatively higher oxygen-surface content as shown in EDS data. The oxidation process of ascorbic acid can be described in the following steps;

(1) The ascorbic acid molecules are firstly diffused and then adsorbed onto the active site of CuO HSs.

(2) The adsorbed ascorbic acid molecules are oxidized to dehydroascorbic acid catalysed by the conversion from $\mathrm{CuO}$ to $\mathrm{Cu}_{2} \mathrm{OOH}$ on the surface.

Next, our attention was focused on the determination of ascorbic acid using CuO HS in a stirred solution of $0.1 \mathrm{NaOH}$ (Fig. S5 $\dagger$ ). The successive amperometric additions of ascorbic acid in a stirred $(0.1 \mathrm{M}) \mathrm{NaOH}$ was shown in Fig. 10a and b. The amperometric currents increased linearly with ascorbic acid concentrations over the concentration ranges $0.1-7 \mathrm{mM} ; I_{\mathrm{p}} / \mu \mathrm{A}$ $=37.24 \mu \mathrm{A} \mathrm{mM}{ }^{-1}+10.59 \mu \mathrm{A}, R^{2}=0.99, N=3$; with the detection limits of $90 \mu \mathrm{M}(\mathrm{S} / \mathrm{N}=3 \sigma)$ and the sensitivity was estimated to be $533 \mu \mathrm{A} \mathrm{mM}{ }^{-1} \mathrm{~cm}^{-2}$. The CuO HS-SPE shows wider concentration ranges and excellent sensitivity towards the oxidation of ascorbic acid than those reported previously. ${ }^{39}$

\subsection{Real application of glucose measurements}

In order to verify the applicability and feasibility of the CuO MFand CuO HS-SPE for determination of glucose and ascorbic acid respectively. $200 \mu \mathrm{L}$ blood serum sample or urine sample was added into $19.8 \mathrm{~mL} 0.1 \mathrm{M} \mathrm{NaOH}$ (see Experimental section). The amperometric current response was recorded at $+0.55 \mathrm{~V}$ ( $v s$. SCE) and a standard addition method was used to determine the glucose and ascorbic acid concentrations. Eight $100 \mu \mathrm{M}$ of standard solutions of glucose or ascorbic acid were successfully added to the cell for slandered addition determination. Each sample was measured three times to overcome systematic error. The calculated results are summarized in Tables 1 and 2 . Therefore, the proposed CuO MF- and CuO HS-SPE sensors are
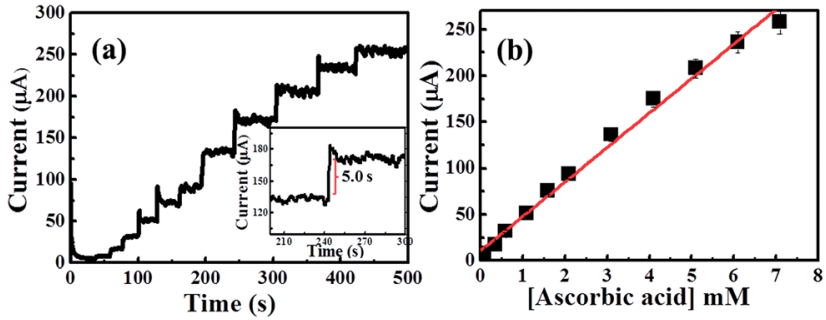

Fig. 10 Typical amperometric current responses of $\mathrm{CuO} \mathrm{HS}$ modified SPE electrode with successive additions ascorbic acid (a) into a stirring $0.1 \mathrm{M} \mathrm{NaOH}$ at $+0.55 \mathrm{~V}$. (b) Analysis of the amperometric profiles in terms of the current as a function of ascorbic acid concentrations.
Table 1 Glucose determination in human blood serum

\begin{tabular}{llll}
\hline Sample & $\begin{array}{l}\text { Spectrophotometric } \\
\text { method }(\mathrm{mM})\end{array}$ & $\begin{array}{l}\text { CuO MF-SPE } \\
(\mathrm{mM})\end{array}$ & RSD\% \\
\hline 1 & 7.99 & 7.89 & 1.89 \\
2 & 5.05 & 5.0 & 1.7
\end{tabular}

Table 2 Ascorbic acid determination of urine samples

\begin{tabular}{llllc}
\hline Sample & Added $(\mathrm{mM})$ & CuO HS-SPE $(\mathrm{mM})$ & RSD\% & Recovery\% \\
\hline 1 & 0.25 & 0.245 & 2.1 & 98 \\
2 & 0.5 & 0.51 & 1.65 & 102 \\
\hline
\end{tabular}

efficient glucose and ascorbic acid detection and could be used in practical applications.

\section{Conclusions}

In this manuscript, the hierarchical $\mathrm{CuO}$ micro-/nanostructures with sphere and flower-like morphology were successfully synthesized via a green solution-phase transformation of $\mathrm{Cu}_{3}(\mathrm{OH})_{4} \mathrm{SO}_{4}$ and $\mathrm{Cu}_{2}(\mathrm{OH})_{3} \mathrm{Cl}$ units in strong alkaline solutions, respectively. A novel hierarchical $\mathrm{CuO}$ microstructures modified screen-printed electrodes (SPE) has been designed upon an anion-dependent approach which effectively optimized the catalytic active surface for an enzyme-less determination of glucose and ascorbic acid. The CuO-SPE exhibited high electrocatalytic capabilities with an excellent selectivity and sensitivity, as well as wide linear range, low detection limit, good stability and reproducibility. In addition, the proposed sensors were successfully applied for glucose and ascorbic acid determinations in real samples, which give great promise for the future practical applications.

\section{Acknowledgements}

The authors would like to acknowledge the support received from British Council and STDF through Newton-Mosharafa Fund, Project ID. 18435.

\section{Notes and references}

1 G. Shen, P.-C. Chen, K. Ryu and C. Zhou, J. Mater. Chem., 2009, 19, 828-839.

2 M. Khairy and S. A. El-Safty, RSC Adv., 2013, 3, 23801-23809.

3 H. Wang and A. L. Rogach, Chem. Mater., 2014, 26(1), 123133.

4 L. Passoni, L. Criante, F. Fumagalli, F. Scotognella, G. Lanzani and F. D. Fonzo, ACS Nano, 2014, 8(12), 1216712174.

5 C. Yuan, J. Li, L. Hou, J. Lin, X. Zhang and S. Xiong, J. Mater. Chem. A, 2013, 1, 11145-11151.

6 Q. Wen, J. Di, Y. Zhao, Y. Wang, L. Jiang and J. Yu, Chem. Sci., 2013, 4, 4378-4382. 
7 M. Khairy, S. A. El-Safty and M. Ismael, Chem. Commun., 2012, 48, 10832-10834.

8 Y. J. Hwang, C. H. Wu, C. Hahn, H. E. Jeong and P. Yang, Nano Lett., 2012, 12(3), 1678-1682.

9 J. Duan, W. Shi, L. Xu, G. Mou, Q. Xin and J. Guan, Chem. Commun., 2012, 48, 7301-7303.

10 S. Lee, V. Sridhar, J. Jung, K. Karthikeyan, Y. Lee, R. Mukherjee, N. Koratkar and I. Oh, ACS Nano, 2013, 7(5), 4242-4251.

11 M. R. Alenezi, S. J. Henley, N. G. Emerson and S. R. P. Silva, Nanoscale, 2014, 6, 235-247.

12 P. Gao and D. Liu, RSC Adv., 2015, 5, 24625-24634.

13 Z. Zhangab and P. Wang, J. Mater. Chem., 2012, 22, 24562464.

14 D. Liu, Z. Yang, P. Wang, F. Li, D. Wang and D. He, Nanoscale, 2013, 5, 1917-1921.

15 A. Pendashteh, M. F. Mousavi and M. S. Rahmanifar, Electrochim. Acta, 2013, 88, 347-357.

16 M. R. Decan, S. Impellizzeri, M. L. Marin and J. C. Scaiano, Nat. Commun., 2014, 5, 4612, DOI: 10.1038/ncomms5612.

17 M. Yanga, J. Hea, X. Hua, C. Yana, Z. Chenga, Y. Zhaoa and G. Zuo, Sens. Actuators, B, 2011, 155, 692-698.

18 (a) S. Sun, Y. Sun, A. Chen, X. Zhang and Z. Yang, Analyst, 2015, 140, 5205-5215; (b) X. Wen, W. Zhang and S. Yang, Langmuir, 2003, 19, 5898-5903; (c) T. Soejima, H. Yagyu, N. Kimizuka and S. Ito, RSC Adv., 2011, 1, 187-190; (d) P. Deka, R. C. Deka and P. Bharali, New J. Chem., 2014, 38, 1789-1793.

19 Z. J. Zhuang, X. D. Su, H. Y. Yuan, Q. Sun, D. Xiao and M. M. F. Choi, Analyst, 2008, 133, 126-132.

20 T.-K. Huang, K.-W. Lin, S.-P. Tung, T.-M. Cheng, I.-C. Chang, Y.-Z. Hsieh, C.-Y. Lee and H.-T. Chiu, J. Electroanal. Chem., 2009, 636, 123-127.

21 H. Wei, J. J. Sun, L. Guo, X. Li and G. N. Chen, Chem. Commun., 2009, 2842-2844.

22 E. Reitz, W. Z. Jia, M. Gentile, Y. Wang and Y. Lei, Electroanalysis, 2008, 20, 2482-2486.
23 X. Wang, C. G. Hu, H. Liu, G. J. Du, X. S. He and Y. Xi, Sens. Actuators, B, 2010, 144, 220-225.

24 G. Liu, B. Zheng, Y. Jiang, Y. Cai, J. Du, H. Yuan and D. Xiao, Talanta, 2012, 101, 24-31.

25 L. Zhang, H. Li, Y. Ni, J. Li, K. Liao and G. Zhao, Electrochem. Commun., 2009, 11, 812-815.

26 P. Ni, Y. Sun, Y. Shi, H. Dai, J. Hu, Y. Wang and Z. Li, RSC Adv., 2014, 4, 28842.

27 J. Chen, R. Zhu, J. Huang, M. Zhang, H. Liu, M. Sun, L. Wang and Y. Song, Analyst, 2015, 140, 5578-5584.

28 C.-J. Weng, P.-H. Hsu, S.-C. Hsu, C.-H. Chang, W. Hung, P.-S. Wu and J.-M. Yeh, J. Mater. Chem. B, 2013, 1, 4983-4991.

29 H. Mao, H. Zhang, J. Liang, D. Liu, S. Wu, Y. Zhang, Y. Zhang, Q. Wu, G. Zhang and X.-M. Song, J. Mater. Chem. $B, 2015,3,5310-5317$.

30 C. W. Foster, J. P. Metters, D. K. Kampouris and C. E. Bank, Electroanalysis, 2014, 26, 262-274.

31 R. O. Kadara, N. Jenkinson and C. E. Banks, Sens. Actuators, $B, 2009,138,556-562$.

32 M. Gómez-Mingot, V. Montiel, C. E. Banks and J. Iniesta, Analyst, 2014, 139, 1442-1448.

33 S. Ito, P. Chen, P. Comte, M. h. Nazeeruddin, P. Liska, P. Péchy and M. Grätzel, Progress in Photovoltaics: Research and Applications, 2007, 15, 603-612.

34 F. E. Galdino, C. W. Foster, J. A. Bonacin and C. E. Banks, Anal. Methods, 2015, 7, 1208-1214.

35 J. P. Metters, E. P. Randviir and C. E. Banks, Analyst, 2014, 139, 5339-5349.

36 F. C. Vicentini, A. E. Ravanini, L. C. S. Figueiredo-Filho, J. Iniesta, C. E. Banks and O. Fatibello-Filho, Electrochim. Acta, 2015, 157, 125-133.

37 Y. Zhang, E. Zhou, Y. Li and X. He, Anal. Methods, 2015, 7, 2360-2366.

38 Y. Ma, M. Zhao, B. Cai, W. Wang, Z. Ye and J. Huang, Biosens. Bioelectron., 2014, 59, 384-388.

39 J. Jiang and X. Du, Nanoscale, 2014, 6, 11303-11309. 